of practical value in problems of air conditioning in such climates. Hythers suitable for temperate climates might be useful to European weather forecasters in more scientific times in the future, when air temperature and discomfort may be forecast separately. The general public does not know that in present-day forecasts the forecaster's references to temperature apply to temperature recorded in a screen designed to remove the vitally important effects of radiation. This fact results often in the anomaly of the forecaster knowing that he has made a technically correct forecast while even intelligent readers of the forecast imagine that it has gone utterly astray. But the hyther system would be more likely to give useful results in the near future in the comparison of different climates with very large contrasts of temperature and humidity.

The usefulness of a scale of discomfort of the type used by Mr. Tyler is apparent from a recent article entitled "Temperature Profiles in Toronto" by W. I:. Knowles Middleton and F. Graham Millar ( $J$. Roy. Ast. Soc. Canada, Sept. 1936). It is an account of observations of air temperature made with a nickel resistance thermometer of small lag, well shielded from radiation, which was mounted two feet from the front of a car 27 inches above the road. The observations were made in a street that runs north. north-west from the shore of Lake Ontario to the northerm limit of the town of Toronto and continues as a paved highway several miles farther in the same direction. Observations of this kind, it may be noted, were made by $\mathrm{H}$. Tollner in Vienna in 1931 (Sitz. Akar. Wiss. Wien, Math. Nat. Kl., Abt. $\mathrm{II}_{\mathrm{a}}, 141$, $1-13 ; 1932$ ). The results of a few selected sets of observations are discussed. 'They are shown as graphs with temperature as ordinates and distances from the lake as abscissw. The elevation of the land is also plotted, so that temperature variations can be related at a glance to the changes of elevation. On a hot sunny day with light southerly wind, a very sharp rise of temperature was observed in the first 200 yards from the lake front and then an average increase of $1 \cdot 3 \mathrm{k}$. in each mile for five miles, after which temperature fell a few degrees in the more countrified surroundings. At such times workers in offices near the lake have the advantage in tem. perature but expcrience a higher humidity and dew point as compared with their families in the residential parts higher up and farther from the lake. In the absence of a sensitive seale of climatic discomfort on the lines of the scalc obtained by Tyler, it is difficult to form an jelea as to which of the two is the better off. Another graph for a clear winter night showed a difference of no less than $27^{\circ} \mathrm{F}$. between the botiom of a valley and its crist, for a difforencer of hright of about 120 feet.

\title{
Chemistry of Essential Oils
}

$\mathrm{I}^{\mathrm{N}}$ the nincteenth Streatfoild Memorial Lecture, delivered at the Institute of Chemistry on November 20, Prof. John Read, of the University of St. Andrews, described a chapter in organic chemistry of extraordinary fascination. $\mathrm{He}_{\mathrm{e}}$ showed how the discovery by Captain Cook of Australia opened a new field of research in the related sciences of botany and chemistry, which was soon appreciated by the early settlers in that continent.

Dr. John White, Surgeon-General to the first settlement at Botany Bay under Governor Phillip, and First Assistant Surgeon D. Considen, both referred in or about 1788 to a large peppermint tree growing around Port Jackson, the essential oil of which bore a close resemblance to that obtained from peppermint (Mentha piperita) long grown in England. This Australian tree, now known as Eucalyptus piperita. or the Sydney peppermint, was supposed to contain the same odoriferous constituent, menthone, as the English tree. But in 1900 this peppermint odour of the genus Eucalyptus was shown by H. G. Smith to be a distinct ketone to which he gave the appro. priate name of piperitone.

Prof. Read compared Smith with Streatfeild as regards his Kentish origin and his unselfish devotion to practical organic chemistry. Migrating to Sydnoy for reasons of health, Smith took up the study of chemistry and devoted himself especially to tho chemistry of the Australian flora. His most remarkable work on the chemical nature of the essential oils of the genus Eucalyptus, which includes three hundred species, has an important bearing on the development of the natural resources of Australia. Certain oils were found to be rich in cineole, phell. andrene, geraniol, citral, pinene and piperitone, whorcas others yichled now chenical constituents peculiar to the Australian flora. Some of these researchos werc rarried out in collaboration with Profs. Read and J. (. Earl, both of whom were former pupils of streatfoikt.

Piperitone, which is a key to the stereochemistry of the menthones, menthols and related substances, is invariably lovorotatory when obtained from encalyptis, whereas from a Himalayan grass Andro. pogon Jwarancusa it was isolated by Simonsen in tho dextrorotatory varisty (1921).

Prof. Tread then showed how the systematic study of tho piperitones as pursued at St. Andrews has disclosod a now approach to the menthols and their congeners. These storeochemical researches offer a clue to the biogenetic relationships of the constituents of essential oils, some of which were traced by Smith and his co-workers. According to J3aker and Smith, the open chain, geranyl acctate, passed into Eucalyptus through Angophorc (an Australian genus of Myrtaceæ) and probably runs through the whole of the oucalypts although sometimes present only in small amounts.

In most species of eucalypts, geraniol may be presumed to finction as the precursor of $l$-piperitol, $l$-piperitone, $\alpha$-phellandrene and allied substances. The delicato control of molccular mochanism takes, however, a different turn in the Indian grasses, where geraniol becomes transformed into the enantiomeric $d$-piperitol, $d$-piperitone and into $\Delta^{4}$-carene. In the present stage of knowledge these subtle differentiations are beyond the powers of the chemical laboratory and appear to be inseparably bound up with vital processes. 'The systrmatic study of these biochemical phenomena is of wide seientific interest and also of considerable industrial significanee.
G. T.M. 